\title{
Measuring the Regional Dimension of Innovation through an Economic Model Based on Rectifying Technology Audits according to the AICTT-RTA Protocol
}

\author{
Stefano De Falco \\ Centre for technology Transfer and Innovation, University of Naples Federico II \\ Via Cinthia M. S. Angelo Naples, Italy \\ sdefalco@unina.it
}

\begin{abstract}
The aim of this paper is to give an answer to the question "how to detect the regional dimension of innovation?". So, in this paper, a method to be used as an operational tool that is able to grasp regional specificities in the innovation process, based on the optimization of measurement activity, is proposed. Evidence in the scientific literature shows that data and indicators are able to quantify the contribution of different regions, identify the different technological profiles of the regions and measure the technological performances of regional systems, the innovative performances of firms and the density and quality of systemic interactions between the main institutional actors, but these items are often not developed through an analytical model of measure control cost based on the optimization of certain influencing factors.
\end{abstract}

The proposed approach is based on two main points:

1) Define the opportune methodology to detect the innovation level of a single firm. For this aim it has been considered the AICTT-RTA protocol. Each SME, is considered as innovative or as non-innovative according to the outcome of a Technology Audit (TA) conducted in compliance with the AICTT-RTA protocol.

2) Determine, starting only from some of the SMEs in a certain monitored area, if the entire area is innovative or not, through TA on a optimal sample size of SMEs analyzed. For this second point the approach uses a bayesian analysis of the Deming cost model.

This approach considers a wide area, industrial or urban, in which SMEs are present and treats it as a lot of $\mathrm{N}$ items.

Through the proposed approach, to characterize the regional innovation it's sufficient to characterize just only some SMEs, however detecting the whole regional innovation profile.

In this paper this aspect is valorized and set in the form of a useful operational tool for regional institutions, innovation managers, entrepreneurs and researchers. Simulation results complement the proposed theoretical model.

Keywords: Regional dimension; Innovation; Bayesan Decision Analysis; Technology Audit.

\section{INTRODUCTION}

It is clear that economic gaps among regions reflect differences in the regions' ability to compete, which increasingly depends upon the innovative capacity of firms and regional systems as a whole (see, among others, Nevenand Gouyette, 1994; Quah, 1996; Fagerberg and 
Verspagen, 1996; Fagerberg et al., 1997). It has been shown that technological variables are able to explain a good deal of the diverging trends in the economic growth across European regions (Fagerberg and Verspagen, 1996). The general indications, drawn from the recent theoretical and empirical literature in this field, state that the process of technological accumulation takes place at local or regional level, even in the era of globalization, and that technological spillovers tend to be highly concentrated at the geographical level (Fagerberg et al., 2005). Despite this, the empirical analysis of innovation activities at a sub-national scale is still at an early stage and this is in large part due to the lack of data able to represent the complex and differentiated phenomenon of innovation at a regional level. Two basic families of S\&T indicators are commonly used to explore technological innovation at regional level: R\&D data - collected through national surveys according to the guidelines set by the Frascati Manual (OECD, 1994) - and patent statistics, the most important body of which is represented by the data provided by the US Patent Office and the European Patent Office. Strengths and weaknesses of R\&D and patent indicators are well known (Archibugi and Pianta, 1996a; OECD, 1996). The advantage of using R\&D data and patents at regional level is based on the following elements: first, consolidated experience in the collection and use of these indicators by statisticians and analysts; second, their comprehensive statistical coverage across countries, industries and technological fields; third, the availability of long time-series datasets which can be used to analyze the dynamic technological performances of firms and industries across regions. Innovation itself is defined as the implementation or introduction of new products, production processes, and business practices (e.g., organizational or marketing methods) in the marketplace (see paragraph 146, OSLO Manual). On the other hand, innovation activities are defined as "the scientific, technological, organizational, financial, and commercial steps" leading to innovation (paragraph 40). Based on these definitions, R\&D and related technological activities are innovation activities in the sense of inputs or precursors to innovation. The OSLO Manual guides the EU community innovation surveys (CIS) and similar surveys in other countries (Arundel et al., 2006). In its desire to acquire expert input, the National Science Foundation held a workshop on June 6-7 2006, entitled "Advancing measures of innovation-knowledge flows, business metrics, and measurement strategies", organized by the NSF's Division of Science Resources Statistics (SRS) with assistance provided under contract by Mary Ellen Mogee, SRI International. The workshop was driven by three main considerations. First, the workshop addressed the challenge by Dr. John H. Marburger III, the Science Adviser to President Bush and Director of the Office of Science and Technology Policy (OSTP), for better data, models, and tools for understanding the US scientific and engineering enterprise in its global context by advancing science and innovation policy research. Second, the workshop was meant to address recommendations in a 2005 study by the National Academies' Committee on National Statistics (CNSTAT) on measuring research and development expenditures in the US economy (NRC 2005b) that SRS should explore the impact of innovation on the US economy and initiate a "program of measurement and research related to innovation". Third, the workshop preceded the OECD Blue Sky II, an international conference, partly sponsored by NSF and organized by OECD's working party of National Experts on Science and Technology Indicators (NESTI) to discuss the development of new and better indicators of science, technology, and innovation (STI) (OECD 2007b). Shortly after the workshop, a new NSF research funding initiative, Science of Science and Innovation Policy (SciSIP), started at the Directorate of Social, Behavioral and Economics Sciences (SBE). The initiative is expected to develop the foundations of an evidence-based platform from which policy makers and researchers can assess the dynamics and impacts of the nation's scientific and engineering enterprise and predict its outcomes. In response to the growing importance and complexity of these issues, the National Science and Technology Council, under the auspices of OSTP, has formed the Interagency Task Group on Science of Science Policy. The 
task group analyzes federal and international efforts in science and innovation policy, identifying tools needed for new indicators, and charting a strategic road map to improve models, and methodologies (OMB2006). A related federal initiative supporting innovation metrics is a US Department of Commerce (DOC) advisory committee, Measuring Innovation in the 21st Century Economy. The DOC committee is studying "metrics on effectiveness of innovation in various businesses and sectors and work to identify which data can be used to develop a broader measure of innovation's impact on the economy." Lastly, the America COMPETES Act has established, among other measures, a President's Council on Innovation and Competitiveness. In addition to policy monitoring and advice, the Council's duties include"developing a process for using metrics to assess the impact of existing and proposed policies and rules that affect innovation capabilities in the United States" as well as "developing metrics for measuring the progress of the Federal government with respect to improving conditions for innovation, including through talent development, investment, and infrastructure development..."

\section{LITERATURE REVIEW}

Innovatory capacity is a critical factor for economic growth, especially if we take into account the fact that an important part of productive growth in advanced nations, as measured in terms of Gross Domestic Product, corresponds to innovation (Freeman, 1994). It can therefore be considered one of the key factors of competitiveness, business survival, growth and employment (Cooke et al., 2000:1; Cooke, 1998: vii;OCDE, 1999:3). Thus it is especially important to find out what components of an R\&D system are most decisive as engines of innovation and what are the factors determining a system's innovatory capacity. As Edquist (2005:201) points out, "given our limited systematic knowledge about determinants of innovation [...] case studies comparing innovation systems of various kinds as well as the determinants of innovation processes within them [...] have great potential". Consequently, these questions have particularly captured the attention of academic researchers and those with political responsibilities throughout recent decades. This has given rise to a series of important studies, both theoretical and empirical: the approach of Furman et al. (2002), the growth theory (Lucas, 1988; Romer, 1990); the cluster bases theory of national competitive advantages (Porter, 1990 and, more specifically, 1998) and the concepts of the national and regional innovation system (Freeman, 1987; Lundvall, 1992; Nelson, 1993; Cooke and Morgan, 1994). Based on this literature and theoretical concepts. a broad range of determinants or explanatory factors of the production of new ideas or knowledge can be defined. The innovation systemic approach underpins, in addition to the national and regional context already mentioned, the institutional framework and the fact that its outcome depends on a broad heterogeneous number of aspects. Therefore, the systemic approach induces us to work with a factor analysis that permits the use of a broad number of interdependent correlated explanatory variables. Moreover, the systemic approach considers determinants as interdependent and highlights the difficulty in classifying them between causes and consequences. For example, successful firms, universities and other public research organizations normally coincide in the same regions (Nelson, 1993) and also industries develop in regions that offer qualified human capital and R\&D services (Freeman, 1994), although it is not clear who induces who. In such a system in which all factors and agents influence each other, traditional econometric models based on individual variables cannot be used. The literature emphasizes the difficulty and weakness of using individual indicators to measure the global concept of innovation (such as patents, R\&D expenditure, the percentage of sales related to new products, etc.). Each of these indicators, although highly correlated, gives a different view of apparently the same subject. It is worthwhile treating the concept and the different elements of an innovation system as something that is not directly observable. A macro-index, AICTT- RTA (Italian acronym for Rendimento Tecnologico Aziendale), has been 
proposed (De Falco et al.) to overcome this weakness, but, although we have a macro index that can detect the level of innovation in an SME, the problem remains of how to qualify an innovative whole region starting from its innovative SMEs. How many measures of innovation, here identified with the result of an audit named TA Technology Audit, are needed to be able to state that a whole region is innovative or not ? This is an attribute sampling inspection problem. We consider inspection as the proposed TA. Measuring innovation in the regional lot of SMEs by a continuous scale is a variable sampling inspection problem. A variable sampling inspection problem can become an attribute sampling problem (Chiuh-Cheng Chyu and IChung Yu, 2006) if the procedure only counts the number of non-innovative SMES to specify limit(s) in the sample and uses this number to decide whether the remaining SMEs of the regional lot are accepted. To design a variable sampling plan, we need to specify the sample size and the acceptance limit(s). If the measured value from the sampling variables falls within the acceptance limit(s), the regional lot is accepted as an innovative area. Otherwise, the lot is rejected. Usually, the acceptance limit(s) will depend on the probability assumptions of the TA model and the sample size. Moskowitz and Tang (1992) used the cost structure proposed by Schmidt et al. (1974) to develop a Bayesian variable acceptance sampling model with the following probability assumptions: the innovative variable has a normal distribution with an unknown mean which is also assumed to be normally distributed. Tagaras (1994) studied a similar cost structure under the same probability assumptions but assumed that the inspection was destructive and therefore the cost of inspection per SME was greater than the cost of rejection per SME. This is not true for TA because it is never destructive.

\section{AICTT - RTA INDEX}

The AICTT, the Italian Association for Technology Transfer Culture (www.aictt.it ), filed a trademark, RTA (Performance Technology Company), which, after a series of national successes, including the certification of IBM Italy, the start of the certification process in Autostrade Tech Lauro spa, is exporting abroad by strengthening the paradigm of the importance of the Made in Italy not only in products but also in services and in particular in a certification service that is unique worldwide, such as that of the RTA. The AICTT-RTA is a parameter used to assess the ability of firms to generate innovation and competitiveness through measurement of the number of patents owned, investments in education, $R \& D$, technology tools and intellectual capital. The analysis is structured across four asset evaluations - Knowledge Economy, Knowledge Engineering, Finance Knowledge, Organization of Knowledge - according to a set of key performance indicators (KPIs) with items for each direction: What results can be achieved? We can get a complete overview of the company, assess strengths and weaknesses, gaps, and possible corrective action. The RTA score is distributed within a score featuring seven classes of performance (from $G$ to $A+$ ), as shown in figure 1, in which each firm is located according to its ability to innovate. The systemic approach Auditor - Consultant is a rating system that allows the company to compete with competitors and offers web-based photography that can represent not only the present but also the future vision that has to be pursued.

For the internationalization of these activities regarding certification, AICTT has opened a branch office in London and works in close collaboration with the Italian Chamber of Commerce in Barcelona and the certification body, Perry Johnson, for the management of audits in AICTT - RTA USA .

One of the first certifications has been carried out abroad on the company Aton Tech Ltd, located in Woodstock Grove London, which is strongly devoted to innovation in the field of international consulting on "Energy Efficiency" applied to various fields, including the energy 
management of cities and applications to railways and local transport, port and airport terminals and rural and isolated areas.

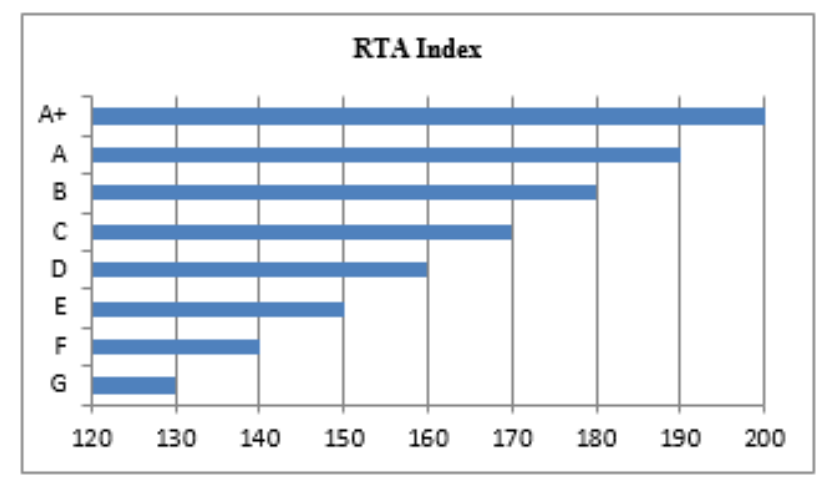

Figure 1 RTA Index

\section{THE PROPOSED APPROACH}

This approach, already followed in other field by authors Chiuhchyu and I-Cheng-Chung Yu in their work "A Bayesian Analysis of the Deming Cost Model with Normally Distributed Sampling Data", considers a wide area, industrial or urban, in which SMEs are present and treats it as a lot of $\mathrm{N}$ items and each item, i.e., each SME, is considered as innovative or as non-innovative according to the outcome of a Technology Audit (TA) conducted in compliance with the AICTTRTA protocol. Then the approach uses a method to determine, starting only from some of the SMEs in the monitored area, if the entire area is innovative or not, through TA on a optimal sample size of SMEs.

In order to manage easily (Van Raan, A.F., 1988) the computational burden, we start from a partitioning approach working in a regional geographic area in which SMEs are situated, consisting of local single zones, lsz, and wide multi-zone areas, wms.

Once a proper Cartesian coordinates system has been selected, the horizontal and vertical dimensions of the investigated area in which SMEs are located have to be selected. Then, by choosing the starting width of the grid, an initial mask indicates the location coordinates where the TA have to be placed. There is often a desire to study specific areas in more depth, because of a bigger population density or the presence of research sources (universities and research bodies). The implemented algorithm, once the base grid has been drawn, therefore waits for one of these two inputs: a density of population function $f(x, y)$ of the examined zone or an indication of the sub-area, chosen by the user, that has to be more precisely investigated.

In the first case, the mean of the f function is evaluated and the algorithm automatically thickens the zones where this mean overcomes a fixed threshold value. In the second case, the information on the zone to thicken is furnished by writing the coordinates of a point in the subarea or by clicking on a point on the graph. Users can choose to continue the thickness process, for a narrower grid, or stop it. Through this algorithm, simple, graphical information on the location where the TA is conducted can be obtained.

In this way, the best configuration of the TA can be designed according to required specifications. Each TA will monitor an independent zone, and the sampling time and the number of TAs are a function of the data confidence level to be obtained.

We have used a cost model using rectifying inspection followed by Chiuhchyu and I-ChengChung $\mathrm{Yu}$ in their work "A Bayesian Analysis of the Deming Cost Model with Normally Distributed Sampling Data". The rectifying inspection plan is a useful tool in statistical quality control (SQC) to assure the average product quality between several stages of a production 
line. A wma rejected by sampling inspection is subject to $100 \%$ inspection. It is also assumed that this inspection is $100 \%$ effective and that all non-innovative SMEs discovered during TA are replaced with innovative SMEs. If a non-innovative SME of a lsz inspection results in a bad measurement set data, the lsz can be restored by the replacement of the non-innovative SME. Any non-innovative SME detected in the TA stages will be replaced by an innovative one.

The decision process of the cost model implemented here consists of two stages: (1) D1: determine the sample size $\mathrm{n}$, and (2) D2: after observing the sampling outcome, deciding whether to stop TA at size n (denoted "Sn") or continuing to audit the N SMEs of the lot (denoted “CN").

The model can be represented as the decision tree shown in figure 2. The notation and definitions of parameters or variables used are as follows:

N: wma size

n: Sample size

$X_{j}$ : Innovative RTA measure of the $j_{t h} l s z$ in the wma

$X_{n}$ : Random vector $\left(X_{1} ; X_{2} ; \ldots ; X_{n}\right)$

U: Mean value of innovative RTA variable, an unknown parameter

$\tau$ : Prior mean of $U$

$\gamma$ : Standard deviation of the prior distribution of $U$

$\tau$ ': Posterior mean of $U$

$\gamma^{\prime}$ : Standard deviation of the posterior distribution of $U$

$Z_{n}$ : Number of "non-innovative" SMEs in the samples

$y:$ Realization of $Z_{n}$

$Z_{N-n:}$ Number of "non-innovative" SMEs in the remainder of the wma

x: Mean of measured values from the samples

$L_{S n}$ : Total cost due to making decision "Sn" on the remainder of the wma

$L_{C N}$ : Total cost due to making decision " $C N$ " on the remainder of the wma

$M(y):$ Number of additional TAs to find $y$ innovative SMEs

$M\left(Z_{N-n}\right):$ Number of additional TAs to find $Z_{N-n}$ non-innovative SMES

$P(U)$ : Probability of an SME being innovative, a function of $U$

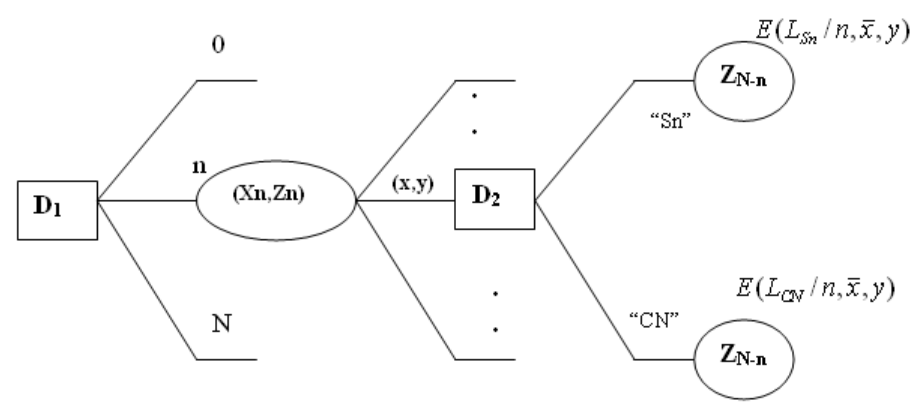

Figure 2 Decision tree of the problem

In this paper, as in most studies in variable sampling plans, it is assumed that the variables have conditional normal distributions, that is $\mathrm{X}_{1} ; \ldots ; \mathrm{X}_{N} \mid \mathrm{U}=\mathrm{u} \sim$ i.i.d.N $\left(\mathrm{u}, \sigma^{2}\right)$. The prior of the unknown mean is also normal, $\mathrm{U} \sim . \mathrm{N}\left(\tau, \gamma^{2}\right)$.

The conditional distribution for the sample mean is normally distributed, $\bar{X} \mid \mathrm{U}=\mathrm{u} \sim$ i.i.d.N $\left(\mathrm{u}, \sigma^{2}\right)$. The unconditional distribution for $\bar{X}$ is also normal, which can be shown as follows:

$\mathrm{X}-U \approx N\left(0, \sigma^{2} / n\right)$ is independent of $\mathrm{U}$ and $\bar{X}=\bar{X}-\mathrm{U}+\mathrm{U} \sim \mathrm{N}\left(\tau, \lambda^{2}+\sigma^{2} / \mathrm{n}\right)$. 
Since the number of non-innovative SMEs, $y$, is a function of $\underline{x}=\left(x_{1} ; x_{2} ; \ldots ; x_{n}\right)$, we have $f\left(u / x_{1}\right.$; $\left.\mathrm{x}_{2} ; \ldots ; \mathrm{x}_{\mathrm{n}} ; \mathrm{y}\right)=\mathrm{f}\left(\mathrm{u} / \mathrm{x}_{1} ; \mathrm{x}_{2} ; \ldots ; \mathrm{x}_{\mathrm{n}}\right)=\mathrm{f}(\mathrm{u} / \mathrm{n}, \mathrm{x})$.

According to Bayes' theorem, the posterior of $U$ given data $\left(\mathrm{x}_{1} ; \mathrm{x}_{2} ; \ldots ; \mathrm{x}_{\mathrm{n}}\right)$ is as follows:

$$
\begin{aligned}
& \mathrm{f}\left(\mathrm{u} / \mathrm{x}_{1}, \mathrm{x}_{2}, \ldots ., \mathrm{x}_{\mathrm{n}}\right) \propto \prod_{\mathrm{i}=1}^{\mathrm{n}} \frac{1}{\sqrt{2 \pi \pi}} \mathrm{e}^{-\frac{1}{2} \frac{\mathrm{x}_{1}-\alpha}{\sigma}} \times \\
& \frac{1}{\sqrt{2 \pi \pi}} \mathrm{e}^{\frac{-1}{2}\left(\frac{\alpha-\tau}{\lambda}\right)} \propto \mathrm{e}^{-\frac{1}{2}\left(\frac{\mathrm{x}-\alpha_{1}}{\sigma}\right)^{2}}
\end{aligned}
$$

Where $\tau^{1}=\left(\left(\sigma^{2} \tau+n \lambda^{2} \underline{x}\right) /\left(\sigma^{2}+n \lambda^{2}\right)\right)$ and $\lambda^{1}=\left(n / \sigma^{2}+1 / \lambda^{2}\right)^{-1 / 2}$. Therefore, the posterior of $U$ is again normally distributed with mean $\tau^{\prime}$ and standard deviation $\lambda^{\prime}$, and sufficient statistics is (n; $\underline{x}$ ) because the posterior of $U$ depends on the data, $\left(\mathrm{x}_{1} ; \mathrm{x}_{2} ; \ldots ; \mathrm{x}_{\mathrm{n}}\right)$, only through the sample mean $\underline{x}$.

In the case of double specification limits, $[a, b]$, the probability of an SME being innovative given $\mathrm{U}=\mathrm{u}, \mathrm{P}(\mathrm{u})=\operatorname{Pr}\{\mathrm{a}<=\mathrm{Xj}<=\mathrm{b} / \mathrm{U}=\mathrm{u}\}=\Phi(\mathrm{b}-\mu / \sigma)-\Phi(\mathrm{a}-\mu / \sigma)$ and the distribution of Zn given $\mathrm{U}=\mathrm{u}$ is binomial $(\mathrm{n}, \mathrm{P}(\mathrm{u}))$, where $\Phi($.$) represents the probability of the standard$ normal distribution.

Although the sampling outcome is ( $\mathrm{n}, \underline{\mathrm{x}}, \mathrm{y}$ ), the total costs for decisions "Sn" and "CN", respectively, are as follows:

$$
\begin{aligned}
& \left(L_{S n} / n, \bar{x}, y\right)=n \times k_{1}+M(y) \times k_{1} \\
& +Z_{N-n} \times k_{2}+M\left(Z_{N-n}\right) \times k_{1} \\
& \left(L_{c n} / n, \bar{x}, y\right)=n \times k_{1}+M(y) \times k_{1} \\
+ & (N-n) \times k_{1}+M\left(Z_{N-n}\right) \times k_{1}
\end{aligned}
$$

By taking the expected total cost as the comparison criterion, decision "Sn" is superior to decision "CN" if $E\left(L_{S a} \mid n, \underline{x}, y\right)<E\left(\mathrm{~L}_{\mathrm{cn}} / \mathrm{n}, \mathrm{x}, \mathrm{y}\right)$. Note that this conclusion remains valid if the lsz is free of the extra TA cost because both terms (1) and (2) contain $M(y)-k_{1}+\mathrm{M}\left(\mathrm{Z}_{\mathrm{N}-\mathrm{n}}\right)-k_{1}$. After some algebraic operations we obtain:

$$
E\left(L_{S n} / n, \bar{x}, y\right) \leq E\left(L_{C N} / n, \bar{x}, y\right)
$$

If and only if

$$
1-E(P(U) / n, \bar{x}) \leq \frac{k_{1}}{k_{2}}
$$

Where $\mathrm{E}(\mathrm{P}(\mathrm{U}) / \mathrm{n}, \underline{\mathrm{x}})=\int_{-\infty}^{\infty}\left[\int_{a}^{b}(1 / \sqrt{2 \pi \sigma}) e^{-\frac{1}{2}(x-\mu)^{2} \times \sigma^{2}} d x\right] \mathrm{f}(\mathrm{u} \mid \mathrm{n}, \mathrm{x}) \mathrm{du}=\operatorname{Pr}\{\mathrm{a}<=\mathrm{Xn}+1<=\mathrm{b} \mid \mathrm{n}, \underline{\mathrm{x}}\}$.

The distribution of $\mathrm{Xn}+1 \mid \mathrm{n}$; $\underline{x}$ is $N\left(\tau^{1}, \sigma^{2}+\left(\lambda^{1}\right)^{2}\right)$ because $X_{n+1}\left|n, \underline{x}=X_{n+1}-U+U\right| n, \underline{x}$ and $x_{n+1}-$ $\mathrm{U} / \mathrm{n}, \underline{\mathrm{X}} \sim \mathrm{N}\left(0, \sigma^{2}\right)$ is independent of the data $(\mathrm{n} ; \underline{\mathrm{x}})$ and the random variable $\left.U \mid \mathrm{n} ; \underline{\mathrm{x}} \sim \mathrm{N} . \tau^{\prime},\left(\lambda^{\prime}\right)^{2}\right)$.

Thus, we have:

$$
\begin{aligned}
& E\left(P(U) / n, \bar{x}=\Phi\left(\left(b-\tau^{\prime}\right) /\left(\sqrt{\sigma^{2}+\left(\lambda^{\prime}\right)^{2} t}\right)\right.\right. \\
& -\Phi\left(\left(a-\tau^{\prime}\right) / \sqrt{\sigma^{2}+\left(\lambda^{\prime}\right)^{2}}\right.
\end{aligned}
$$

Furthermore, because $\tau^{\prime}=\left(\left(\sigma^{2} \tau+n \lambda^{2} x\right) /\left(\sigma^{2}+n \lambda^{2}\right)\right)$ and $\left(\lambda^{\prime}\right)$ is independent of $\underline{x}, E(P(U) / n, \underline{x}$ reaches maximum when $\tau^{1}=(a+b) / 2$ which gives $\underline{x}=\left((a+b)+\left(\sigma^{2}+n * \lambda^{2}\right)-2 \sigma^{2} \tau\right) /\left(2 n^{*}\right.$ $\left.\lambda^{2}\right)$.The value of $E(P(U) / n, x)$ goes down as $\tau^{\prime}$ moves further away from $(a+b) / 2$. The interval, $\left[\mathrm{x}_{\mathrm{L}}, \mathrm{X}_{\mathrm{R}}\right]$, for choosing decision "Sn" under the sample size of $\mathrm{n}$ can be computed as follows: 


$$
\begin{aligned}
& \bar{x}_{L}=\min \left\{\bar{x}: E(P(U) / n, \bar{x}) \geq 1-\frac{k_{1}}{k_{2}}, \bar{x} \leq \bar{x}^{*}\right\} \text { and } \\
& \bar{x}_{R}=\max \left\{\bar{x}: E(P(U) / n, \bar{x}) \geq 1-\frac{k_{1}}{k_{2}}, \bar{x} \leq \bar{x}^{*}\right\}
\end{aligned}
$$

In other words

$$
1-E(P(U) / n, \bar{x}) \leq \frac{k_{1}}{k_{2}} \text { if and only if } \bar{x} \in\left[\bar{x}_{L}, \bar{x}_{R}\right]
$$

The objective function of the model can be obtained by applying the Bayesian decision rule to the decision tree given in Figure 2.

$$
\begin{aligned}
& \operatorname{Min}_{0 \leq n \leq N} \int_{-\infty}^{\infty}\left[\sum_{y=0}^{n}\left\{\operatorname{Min}\left[E\left(L_{s n} / n, \bar{x}, y\right), E\left(L_{c n} / n, \bar{x}, y\right)\right]\right\}\right. \\
& \times \operatorname{Pr}\{y / n, \bar{x}\}] \times g(\bar{x} / n) d \bar{x}
\end{aligned}
$$

where $\mathrm{g}(\mathrm{x} / \mathrm{n})$ is the p.d.f. of the sufficient statistic $\mathrm{x}$. We want to determine a sample size $\mathrm{n}^{*}$ between 0 and $\mathrm{N}$ that finds the Minimum Expected Total Cost (METC) with respect to Eq. (6). This sample size $n^{*}$ is referred to as the Optimal Sample Size (OSS). Equation (6) can be simplified further as follows:

$$
\begin{aligned}
& \left\{\operatorname { M i n } _ { 0 \leq n \leq N } \left\{n \times k_{1}+(N-n) \times\left[E\left(\frac{1}{P(U)}\right)-1\right] \times k_{1}\right.\right. \\
& +(N-n) \times \int_{-\alpha}^{\alpha} \operatorname{Min}\left[(1-E(P(U) / n, \bar{x})) \times k_{2}, k_{1}\right] \\
& \times g(\bar{x} / n) \times d \bar{x}+n \times k_{1} \times \int_{-\alpha}^{\alpha} E\left(\frac{1}{P(U)} / n, \bar{x}\right) \times \\
& (1-E(P(U) / n, \bar{x})) \times g(\bar{x} / n) \times d \bar{x}\}
\end{aligned}
$$

If the lsz is free of the extra TA cost, Eq. (7) does not contain the second and the fourth terms. The computation for Eq. (7) determines the OSS. After observing the sampling outcome $\left(\mathrm{x}_{1} ; \ldots\right.$ , $\left.\mathrm{X}_{\mathrm{oss}}\right)$, we compute $\underline{\mathrm{x}}_{\mathrm{oss}}=\left(\mathrm{x}_{1}, \ldots, \mathrm{X}_{\mathrm{oss}}\right) / \mathrm{OSS}$.

If 1 - $\mathrm{E}\left(\mathrm{P}(\mathrm{U}) / \mathrm{OSS}, \underline{\mathrm{x}}_{\mathrm{oss}}<=\mathrm{k}_{1} / \mathrm{k}_{2}\right.$ or $\mathrm{x}_{\mathrm{oss}} \in\left[\mathrm{x}_{\mathrm{L}}, \mathrm{x}_{\mathrm{R}}\right]_{-}$, we should choose $\mathrm{D}_{2}=$ "Sn." Otherwise, we choose $\mathrm{D}_{2}=$ "CN."

There is no closed form for Eq. (7) and Simpson's three-eighths integration approximation rule is applied to compute the integrals in this formula. During the computations, an accurate numerical table for standard normal distribution is helpful in computational efficiency because the posterior distribution of parameter $U$ and the marginal distribution of sample mean $\bar{X}$ have normal distributions. Let's suppose that $\left(\bar{x}_{1}, \cdots \bar{x}_{M}\right)$ are used to represent the values of $\bar{X}$ in the numerical integration. The value of the third term of Eq. (7) for a sample size of $n$ can be computed as follows:

Sum3 = 0; $\{$ Begin $\}$

For $j=1$ to $M$

If $\bar{x}_{j} \in\left[\bar{x}_{L}, \bar{x}_{R}\right]$ compute $\left(1-E\left(P(U) / n, \bar{x}_{j}\right) \times k_{2}\right.$ And add it to Sum3

Else Sum $3=$ Sum $3+k_{1}$;

Sum3 $=(N-n) *$ Sum3. $\{$ End $\}$

The value of Eq. (7) as a function of sample size $n$ behaves in the same way as Figure 2, but the curve may not be smooth locally. Binary search for finding the METC and its corresponding OSS is not suitable for application in such a situation. To reduce computational time and avoid missing the METC and its corresponding OSS, we adopt the following search strategy.

We start with $n=0$. We compute the values of Eq. (7) for sample sizes with multiples of 10 . If the value goes up for three consecutive searches or to the lot size $\mathrm{N}$, then the algorithm stops searching further and takes the sample size with minimum value up to the present search. If 
the sample size with minimum values $10 * \mathrm{k}$, then the algorithm searches the OSS within [10* $(\mathrm{k}-1), 10 *(\mathrm{k}+1)]$ for $1<=\mathrm{k}<\mathrm{N},\left[0,10^{*}(\mathrm{k}+1)\right]$ for $\mathrm{k}=0$, and $[\mathrm{N}-10 ; \mathrm{N}]$ for $\mathrm{k}=\mathrm{N}$.

The proposed method allows an attribute sampling model based on the variable measurement data to be established. In other words, the model will use the information on the number of non-innovative SMEs that comes from the variable measurement data in the sample. This attribute sampling model needs the probability of a component being conforming, $P(U)$, which is a function of parameter $U$ and is a random variable of the following form:

$$
P(U)=\int_{a}^{b} \frac{1}{\sqrt{2 \pi \sigma}} e^{-\frac{1}{2}\left(\frac{x-U}{\sigma}\right)} d x
$$

There is no closed form for the continuous distribution of $\mathrm{P}(\mathrm{U})$. The following method computes an approximate discrete probability distribution of $\mathrm{P}(\mathrm{U})$.

The conditional probability under $U=u, P(U)=\Phi((b-u) / \sigma)-\Phi((a-u) / \sigma)$ is maximum when $u$ $=(\mathrm{a}+\mathrm{b}) / 2$ and decreases as $\mathrm{u}$ moves away from $(\mathrm{a}+\mathrm{b}) / 2$. Partition the interval, $[0,1]$, into $\mathrm{M}$ subintervals of equal length with $\mathrm{p}_{\mathrm{m}}=\mathrm{m} / \mathrm{M},(\mathrm{m}=1,2, \ldots, \mathrm{M})$. Let $\mathrm{u}_{\mathrm{m}}{ }^{\mathrm{L}}=\operatorname{Min}\{\mathrm{u}: \mathrm{P}(\mathrm{u})>=$ $\mathrm{m} / \mathrm{M}\}$ and $\mathrm{u}_{\mathrm{m}}^{\mathrm{U}}=\operatorname{Max}\left\{\mathrm{u}: \mathrm{P}(\mathrm{u})>=\mathrm{m} / \mathrm{M}\right.$. We have $\left.\operatorname{Pr}\left\{\mathrm{P}(\mathrm{U})>=\mathrm{p}_{\mathrm{m}}\right\}=\Phi\left(\mathrm{u}_{\mathrm{m}}^{\mathrm{U}}-\tau\right) / \lambda\right)-\Phi\left(\mathrm{u}_{\mathrm{m}}^{\mathrm{L}}-\tau\right) /$ $\lambda)$ and $\operatorname{Pr}\left\{P(U)=p_{m}\right\}=\operatorname{Pr}\left\{P(U)>=p_{m-1}\right\}-\operatorname{Pr}\left\{P(U)>=p_{m}\right\}$.

After obtaining the approximation discrete distribution for $\mathrm{P}(\mathrm{U})$, we observe the sampling data $\left(\mathrm{x}_{1}, \mathrm{x}_{2}, \ldots, \mathrm{x}_{\mathrm{n}}\right)$ and compute the number of non-conforming units in the sample, $\mathrm{y}=\sum_{k=1}^{n} y_{k}$ where $\mathrm{y}_{\mathrm{k}}=0$ if $\mathrm{a}<=\mathrm{x}_{\mathrm{k}}<=\mathrm{b}$ and $\mathrm{y}_{\mathrm{k}}=1$ otherwise. In the attribute sampling model, (n, y) are sufficient statistics, and the probability distribution of $\mathrm{Y} / \mathrm{n}, \mathrm{p}_{\mathrm{m}}$ is binomial. Using the decision analysis similar to the variable sampling model, we conclude the following statements:

$$
\begin{aligned}
\text { Model objective is } & \operatorname{Min}_{0 \leq n \leq N} \sum_{0 \leq y \leq n}\left[\operatorname{Min}\left(E\left(L_{S N} / n, y\right), E\left(L_{C N} / n, y\right)\right)\right] \\
& \times \operatorname{Pr}\{y / n\} .
\end{aligned}
$$

The posterior distribution of $\mathrm{P}(\mathrm{U})$ has the following property.

For any prior distribution of $P(U), E(P(U) / n, y)$ increases in $n$ (y fixed) and $E(P(U) / n, y)$ decreases in $\mathrm{y}$ ( $\mathrm{n}$ fixed). We can use this property to facilitate the computations for the attribute sampling model.

By (S2) and the property stated previously, if $1-\mathrm{E}(\mathrm{P}(\mathrm{U}) / \mathrm{n}, 0)>\mathrm{k} 1 / \mathrm{k} 2$, then decision "CN" is better regardless of the sampling outcome. Likewise, by (S2) and the property, if $1-E(P(U) / n$, $\mathrm{n})<=\mathrm{k} 1 / \mathrm{k} 2$, zero TA is better than taking sample size $\mathrm{n}$ because any sampling outcome in this sample size will not change the decision "Sn." For the other case, there exists an acceptance number, c, $0<\mathrm{c}<\mathrm{n}$, satisfying $1-\mathrm{E}(\mathrm{P}(\mathrm{U}) / \mathrm{n}, \mathrm{c})<=\mathrm{k} 1 / \mathrm{k} 2$ and $1-\mathrm{E}(\mathrm{P}(\mathrm{U}) / \mathrm{n}, \mathrm{c}+1)>=\mathrm{k} 1 / \mathrm{k} 2$. We choose "Sn" if $\mathrm{y}<=\mathrm{c}$ and choose "CN" otherwise.

\section{SIMULATION RESULTS}

We characterize the innovation profile of an area through 500 SMEs on which a TA according to AICTT-RTA methodology is been conducted. ${ }^{1}$

Therefore, $\mathrm{N}=500$ for the wma.

\footnotetext{
1The TA, based on AICTT-RTA methodology, can also be conducted off-line through databases available to the Association AICTT (http://www.aictt.it/) relative to the profiles of companies that have participated in regional and national bids for funding. Without conducting a real TA, the AICTT-RTA methodology is applied through a picture of the company detected from these databases and then by simulation, we can verify which RTA score is assigned to these companies.
} 
For example, we assume that the tolerance range considered for the RTA measures is characterized by a specification of $(a, b)=(23.95,24.05)$ relative to the worst class of RTA, the $\mathrm{G}_{\text {class }}^{2}$. The audit cost per SME is $\mathrm{k}_{1}=€ 9.25$, and the low innovation cost (the cost related to the not achieving of the RTA level) of $\mathrm{k}_{2}$ is estimated at $€ 72.40$ each. The low innovation cost includes old equipment, absence of a system for documentation of innovation, lack of proper training, no tracking of projects, and so on. We want to refer to three RTA auditors $(A, B$, and C). We assume that the purchase cost per SME is the same for all three auditors. Based on the technologies and data, we consider the values of three parameters, $(\sigma, \tau, \gamma)$ with respect to the three auditors as shown in Table I.

Table I METC and OSS for RTA TA by RTA Auditors A,B and C

\begin{tabular}{cccccc}
\hline $\begin{array}{c}\text { RTA } \\
\text { Auditor }\end{array}$ & $\sigma$ & $\tau$ & $\gamma$ & OSS & $\begin{array}{c}\text { METC } \\
{[€]}\end{array}$ \\
\hline A & 0.0231 & 24.0241 & 0.00962 & 42 & 4.835 \\
B & 0.0282 & 24.0137 & 0.01260 & 40 & 4.807 \\
C & 0.0235 & 24.0249 & 0.01270 & 37 & 5.063 \\
\hline
\end{tabular}

The value of $\tau$ could refer to the total mean performance Technology Audits in previous lots, and $\gamma$ could refer to the lot-by-lot variability of the mean performance Technology Audit. The computational results show that the best auditor is B with METC at $€ 4,807$ and an optimal sample size OSS $=40$. In addition, by Eq. (4), we obtain $\left[\mathrm{x}_{\mathrm{L}} ; \mathrm{x}_{\mathrm{R}}\right]=[23,9801 ; 24.0165]$. Assuming that after TA the samples of 40 lszs by the auditor B, the sample mean and the number of noninnovative SMEs are $\underline{x}=23: 985$ and $y=7$, respectively. Because $\underline{x}=23: 985$ is within the interval $\left[\mathrm{x}_{\mathrm{L}} ; \mathrm{x}_{\mathrm{R}}\right]$, we could stop TA and close the remaining lszs of the lot. Another computation results in the two expected total costs $\mathrm{E}\left(\mathrm{LSn}_{\mathrm{Sn}} / \mathrm{OSS} ; \underline{\mathrm{x}}\right)=€ 4,675$ and $\mathrm{E}\left(\mathrm{L}_{\mathrm{CN}} / \mathrm{OSS} ; \underline{\mathrm{x}}\right)=€ 5,424$, respectively. The expected number of extra TAs for compensation is $\mathrm{E}(\mathrm{M}(\mathrm{y}) / \mathrm{OSS} ; \underline{\mathrm{x}})+\mathrm{E}\left(\mathrm{M}\left(\mathrm{Z}_{\mathrm{N}}\right.\right.$ $\mathrm{n} /$ OSS; $\underline{\mathrm{x}})=86,3$. All three values are obtained by applying the Simpson's three-eighths approximation integration rule to the formulae given in the following.

The objective function is:

$$
\operatorname{Min}_{0 \leq n \leq N} \int\left[\sum_{y=0}^{n}\left\{\operatorname{Min}\left[E\left(L_{S n} \mid n, \bar{x}, y\right), E\left(L_{C N} \mid n, \bar{x}, y\right)\right]\right\} \cdot \operatorname{Pr}\{y \mid n, \bar{x}\}\right] g(\bar{x} \mid n) d \bar{x}
$$

By taking expectation on Eqs. (1) and (2) we obtain:

$$
\begin{aligned}
& E\left(L_{s n} / n, \bar{x}, y\right)=n \times k_{1}+E(M(y) \mid n, \bar{x}, y) \cdot k_{1} \\
& +E\left(Z_{N-n} \mid n, \bar{x}, y\right) \cdot k_{2}+E\left(M\left(Z_{N-n}\right) \mid n, \bar{x}, y\right) \cdot k_{1} \\
& \quad E\left(L_{c n} / n, \bar{x}, y\right)=n \cdot k_{1}+E(M(y) / n, \bar{x}, y) \cdot k_{1} \\
& +(N-n) \times k_{1}+E\left(M\left(Z_{N-n}\right) / n, \bar{x}, y\right) \cdot k_{1}
\end{aligned}
$$

We need to compute:

(i) $E\left(Z_{N-n} \mid n, \bar{x}, y\right)$ :The expected number of "non-innovative" SMEs in the remaining N-n SMEs of the wma given the information $(n, \bar{x}, y)$

(ii) $E(M(y) \mid n, \bar{x}, y)$ : The expected number of extra TAs to obtain y "innovative SMEs" given the information $(n, \bar{x}, y)$

(iii) $E\left(M\left(Z_{N-n}\right) / n, \bar{x}, y\right)$ : The expected number of extra TAs to obtain ZN-n "innovative SMEs" given the information $(n, \bar{x}, y)$ 
(iv) $\sum_{y=0}^{n} E(M(y) y \mid n, \bar{x}) \cdot \operatorname{Pr}\{y \mid n, \bar{x}\}$

We have:

(i)

$$
E\left(Z_{N-n} \mid n, \bar{x}, y\right)=(N-n)(1-E(P(U) \mid n, \bar{x})
$$

For any $\mathrm{U}=\mathrm{u}$, we have:

$$
E\left(Z_{N-n} \mid n, \bar{x}, y, U=u\right)=E\left(Z_{N-n} \mid n, u\right)=(N-n)(1-P(u))
$$

Therefore:

$$
E\left(Z_{N-n} \mid n, \bar{x}, y, U\right)=(N-n)(1-P(U))
$$

$\left.E\left(Z_{N-n} \mid n, \bar{x}, y\right)=E\left[E\left(Z_{N-n} \mid n, \bar{x}, y, U\right) \mid n, \bar{x}, y\right)\right]=(N-n)(1-E(P(U) \mid n, \bar{x}, y))=(N-n)(1-E(P(U) \mid n, \bar{x})$,

$$
\begin{gathered}
E(M(y) \mid n, \bar{x}, y)=y \cdot E((1 / P(U)) \mid n, \bar{x}) \\
E(M(y) \mid n, \bar{x}, y, U=u)=y \cdot 1 / P(u) \\
E(M(y) \mid n, \bar{x}, y)=E[E(M(y) \mid n, \bar{x}, y, U) \mid n, \bar{x}, y)]=E(y \cdot 1 / P(U) \mid n, \bar{x}, y) \\
=y \cdot E(1 / P(U) \mid n, \bar{x}, y)=y \cdot E(1 / P(U) \mid n, \bar{x}) \\
=y \cdot \int_{-\infty}^{+\infty} \frac{1}{P(u)} \cdot f(u \mid n, \bar{x}) d u \\
E\left(M\left(Z_{N-n}\right) / n, \bar{x}, y\right)=(N-n)\left[E\left(\frac{1}{P(U)} / n, \bar{x}\right)-1\right] \\
E\left(M\left(Z_{N-n}\right) / n, \bar{x}, y, U=u\right)=(N-n) \frac{1-P(u)}{P(u)}=(N-n)\left(\frac{1}{P(u)}-1\right) \\
E\left(M\left(Z_{N-n}\right) / n, \bar{x}, y\right)=E\left[E\left(M\left(Z_{N-n}\right) / n, \bar{x}, y, U\right) / n, \bar{x}, y\right)=(N-n)\left[E\left(\frac{1}{P(u)} / n, \bar{x}\right)-1\right] \\
+\sum_{y=0}^{n} E(M(y) y \mid n, \bar{x}) \cdot \operatorname{Pr}\{y \mid n, \bar{x}\}=\sum_{y=0}^{n} y \cdot E\left(\frac{1}{P(U)} \mid n, \bar{x}\right) \cdot \operatorname{Pr}\{y \mid n, \bar{x}\} \\
=E\left(\frac{1}{P(U)} \mid n, \bar{x}\right) \cdot \sum_{y=0}^{n} y \cdot \operatorname{Pr}\{y \mid n, \bar{x}\}=E\left(\frac{1}{P(U)} \mid n, \bar{x}\right) \cdot n \cdot(1-E(P(U) \mid n, \bar{x})
\end{gathered}
$$

The expected extra TA ratio at the second stage decision is 0.1765 which is obtained by dividing the expected number of extra TAs by the lot size $\mathrm{N}=500$. The user will pay the extra TA cost but no extra purchase cost.

In the following, a numerical analysis for RTA Auditor B under the Deming cost model is proposed.

The model parameters considered in the analysis are cluster size $\mathrm{N}$, cost ratio $\mathrm{k}_{1} / \mathrm{k}_{2}$, and probability model parameters $(\sigma, \tau, \gamma)$. A comparison on METC and OSS between the variable sampling model and the corresponding attribute sampling model under the same probability assumptions and cost structure is also presented. 


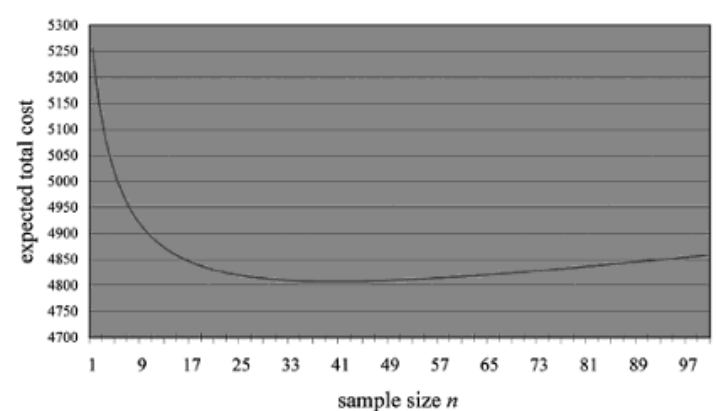

Figure 3 Expected cost for RTA Auditor B in sample size n

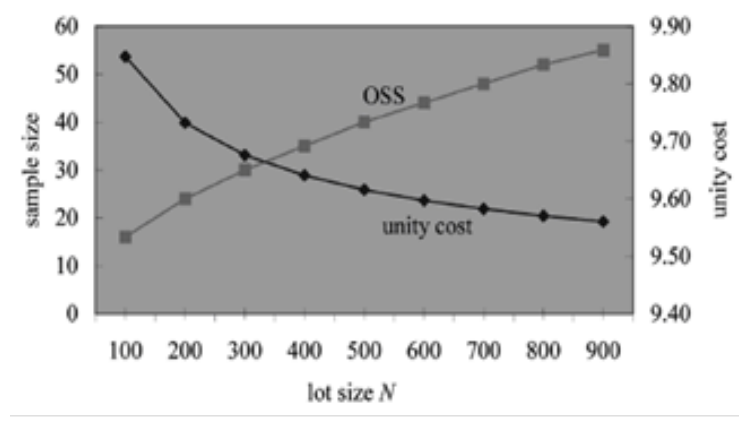

Figure 4 OSS and unity cost versus lot size $\mathrm{N}$.

Figure 3 shows the variation of expected total cost with respect to different sample sizes for RTA Auditor B under lot size $\mathrm{N}=500$. Our experimental results show that the expected cost as a function of the sample size behaves in the same way as the curve shown in Figure 4. This result provides a good reference for us to develop an efficient algorithm for finding the METC and its corresponding OSS. Unity cost is defined as the METC per unit, that is, METC $=\mathrm{N}$.

Figure 4 illustrates the behavior of the unity cost and the OSS as the value of $\mathrm{N}$ varies. The unity cost decreases and is convex in $\mathrm{N}$, which implies that the marginal effect on the cost saving of this model decreases as the lot size $\mathrm{N}$ becomes larger and larger. On the other hand, the OSS is concave and increases in lot size $\mathrm{N}$. In other words, the marginal increase of the OSS slows down as $\mathrm{N}$ increases.

Figure 5 depicts the effects of the cost ratio $\mathrm{k} 1=\mathrm{k} 2$ with fixed $\mathrm{k} 2$ and $\mathrm{N}=500$. The OSS decreases approximately linearly whereas the unity cost increases approximately linearly as the cost ratio increases. It is quite sensible that the increase in $\mathrm{k} 1$ will increase the METC and reduce the size of OSS.

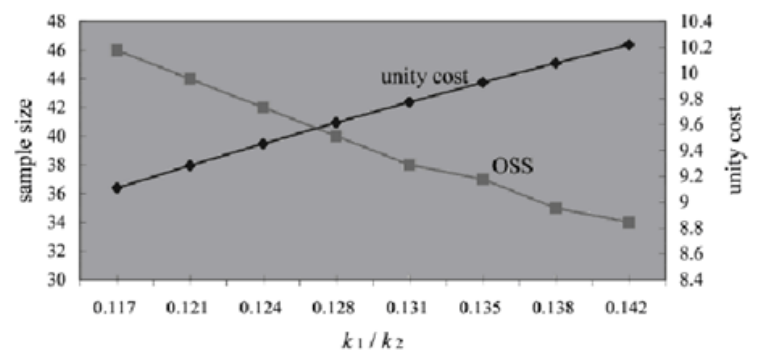

Figure 5 OSS and unity cost versus cost ratio $\mathrm{k} 1 / \mathrm{k} 2$ with $\mathrm{k} 2=72.4$

Figure 6 presents the effect of the standard deviation $\sigma$ of the TA for the SMEs when the process mean $\tau$ does not deviate much from the center of RTA specification limits. For RTA Auditor B, $\tau=24,0137$ and $((a+b) / 2)=24$. When $\sigma$ increases, the probability of an SME being conforming becomes smaller and this will make both the OSS and the unity cost increase.

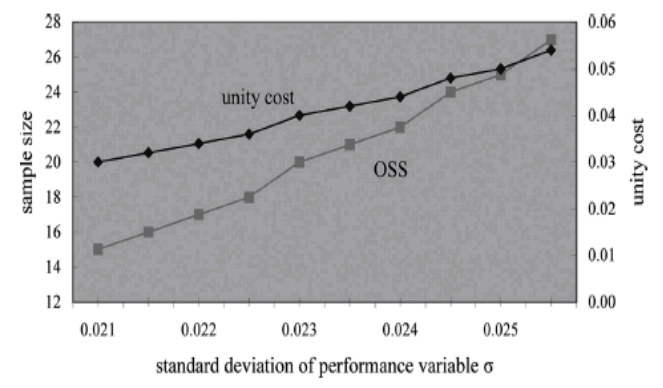

Figure 6 Oss and unity cost versus standard deviation $\sigma$ 
A similar situation with the same reasoning happens as the prior mean $\tau$ moves further away from the specification mean as shown in Figure 7. The parameter, $\gamma$, represents the degree of uncertainty for the unknown mean, $\mathrm{U}$.

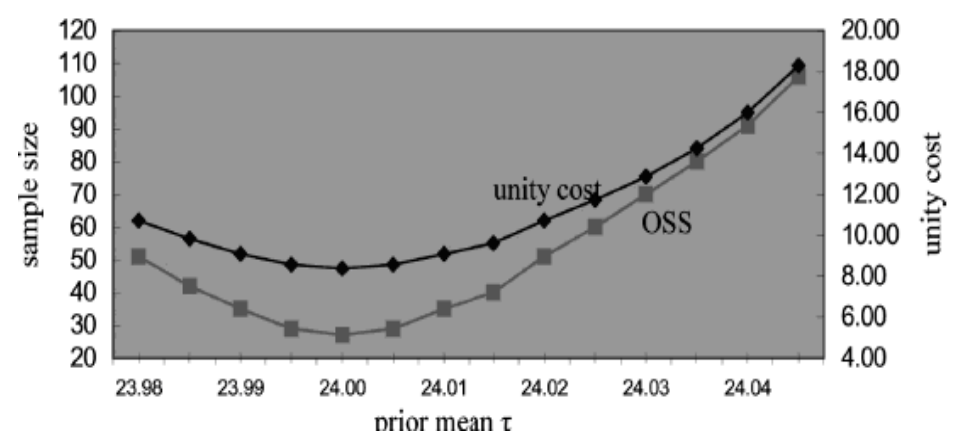

Figure 7 Oss and unity cost versus prior mean $\tau$

Figure 8 indicates that the increase of $\gamma$ reduces the probability of an SME being innovative and thus the METC increases, but the OSS is insensitive to the variation of $\gamma$. Table II shows that the METC and the OSS for the variable sampling model are smaller than those for the corresponding attribute sampling model under the same probability model and cost structure.

Table II Comparison between two sampling models for RTA TA by Auditor B

\begin{tabular}{ccccccc}
\hline Wma size N & OSS & $\begin{array}{c}\text { Acceptance limits } \\
{\left[\mathrm{x}_{\mathrm{L}} ; \mathrm{x}_{\mathrm{R}}\right]}\end{array}$ & $\begin{array}{c}\text { Unity } \\
\text { cost }\end{array}$ & OSS & $\begin{array}{c}\text { Acceptance } \\
\text { number [c] }\end{array}$ & $\begin{array}{c}\text { Unity } \\
\text { cost }\end{array}$ \\
\hline 100 & 16 & {$[23.9754,24.0161]$} & 9.85 & 25 & 4 & 10.18 \\
200 & 24 & {$[23.9780,24.0162]$} & 9.73 & 46 & 7 & 10.02 \\
300 & 30 & {$[23.9791,24.0163]$} & 9.68 & 61 & 9 & 9.94 \\
400 & 35 & {$[23.9797,24.0164]$} & 9.64 & 68 & 10 & 9.88 \\
500 & 40 & {$[23.9801,24.0165]$} & 9.62 & 83 & 12 & 9.84 \\
600 & 44 & {$[23.9804,24.0165]$} & 9.60 & 91 & 13 & 9.81 \\
700 & 48 & {$[23.9807,24.0165]$} & 9.58 & 98 & 14 & 9.78 \\
800 & 52 & {$[23.9809,24.0165]$} & 9.57 & 106 & 15 & 9.76 \\
900 & 55 & {$[23.9810,24.0165]$} & 9.56 & 114 & 16 & 9.74 \\
\hline
\end{tabular}

This is because in this study the attribute information is derived from the variable information. In such a situation, the same power can be achieved with a sample size in a variable acceptance sampling plan that is far smaller than the sample size for a derived attribute acceptance sampling plan.

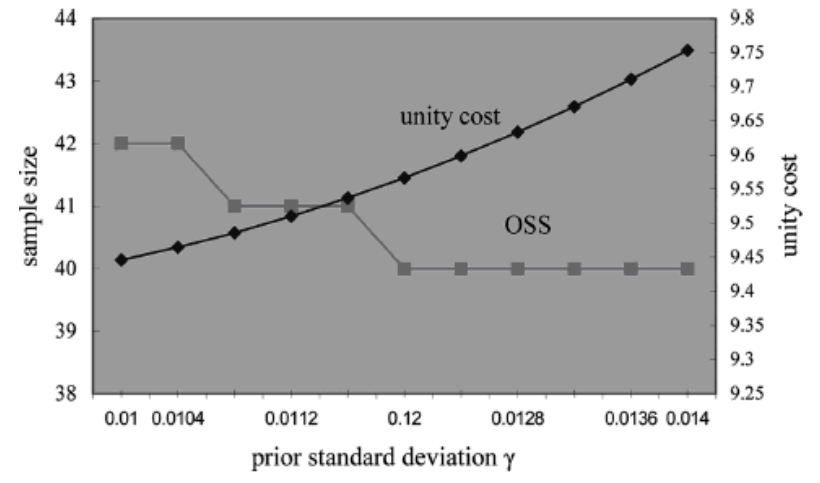

Figure 8 Oss and unity cost versus prior standard deviation $\gamma$

\section{IMPLEMENTATION FOR RTA MONITORING}

A remote measurement system that is characterized by mobile distributed architecture could be implemented to monitor the RTA index, refreshing it, according to the economic requirements described in the paper and sending it to a central data collector. 
For this purpose, an industrial or urban zone could be portioned as reported in Figure 9 and mapped by a distributed system of mobile probes that continuously pick RTA values from SMEs that are present in that area and sent through a GPS card to a remote server for data analysis and decision making, as reported in Figures 10 and 11.

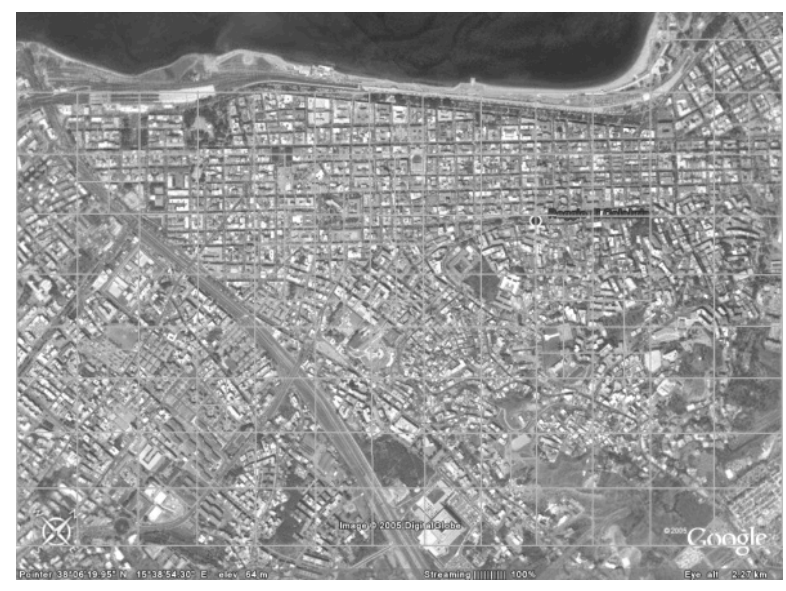

Figure 9: SMEs Configurable area partitioning

The system we propose consists of a number of mobile probes that acquire data on RTA values, the probe's position and time (acquisition system) and send them to a remote server (transmission infrastructure). The latter is equipped with a database management system (DBMS) and software analysis system (as a whole, a data management system) that allows information to be extracted.
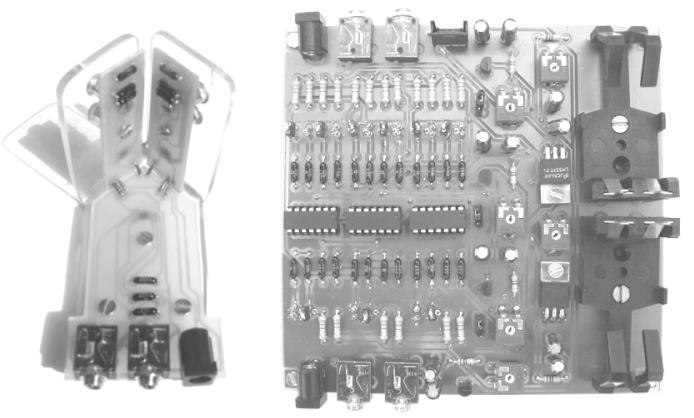

Figure 10: RTA measurement system

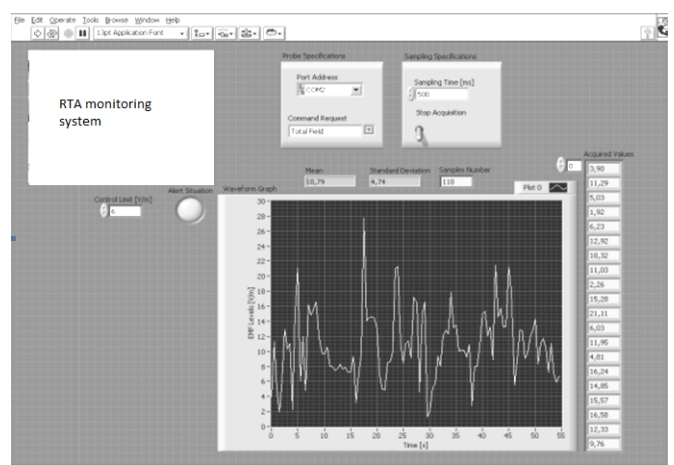

Fig. 11: Remote server gathering RTA data sent by clients mapping of a large area

Each mobile acquisition system should be equipped with a GPS module for localization purposes, and a wideband probe to measure RTA levels. Wherever possible, connections between devices could be established through optical links to minimize interference on measurements caused by electrical coupling.

\section{CONCLUSIONS}

The possibility of obtaining aggregated information constitutes an essential tool for defining the innovation profile of an entire urban or industrial zone level.

The only obstacle that must be overcome is the cost of measures.

In this paper a cost model using a Bayesian approach, followed in a different field by Chiuhchyu and I-Cheng-Chung $\mathrm{Yu}$, consisting of a two-stage decision that minimizes the expected total cost of innovation's measurement, is proposed. This gives the operational tool used to validate 
with statistical confidence a single zone through the appropriate dimension of the sample to be measured and, in a second step, provides a practical procedure to extend the results related to the single zone measures to the total wide area.

The wide area to be monitored is therefore divided into several local zones where the single sensing unit has the task of acquiring a fixed number of data. Sampling time and location of measurement points depend on topographical and environmental knowledge and the performance to be achieved. The prior distribution for the unknown mean is also assumed to be normally distributed. A numerical result has been presented to show how the model parameters, such as wide multi-zone area size, prior distribution, and cost ratio, affect the optimal sample size and the minimum expected total cost. In addition, in the model application, a comparison of three different RTA auditors has been developed according to AICTT-RTA protocol proposed by the Italian Association for technology Transfer Culture Promotion, AICTT.

\section{References}

Acs, Z.J., Audretsch, D.B., 1988. Innovation in large and small firms: an empirical analysis. The American Economic Review 78, 678-690.

Acs, Z., Anselin, L., Varga, A., 2002. Patents and innovation counts as measures of regional production of new knowledge. Research Policy 31, 1069- 1085.

Acs, Z., Audretsch, D., Feldman, M., 1992. Real effect of academic research: comment. The American Economic Review 82 (1), 363-367.

Amable, B., Petit, P., 2001. The diversity of social systems of innovation and production during the 1990s. In: Paper Presented at the DRUID Conference, Aalborg, June, 2001.

Anselin, L., Varga, A., Acs, Z., 1997. Local geographic spillovers between university research and high technology innovations. Journal of Urban Economics (42), 422-448.

Archibugi, D., 1992. Patenting as an indicator of technological innovation: a review. Science and Public Policy 19, 357-368.

Archibugi, D., Pianta, M., 1996a. Measuring technological change through patents and innovation surveys. Technovation 16, 115-121.

Archibugi, D., Pianta, M., 1996b. Innovation surveys and patents as technology indicators: the state of the art. In: Innovation, patents and technological strategies. Paris, OECD.

Arundel, A., Kabla, I., 1998. What percentage of innovations are patented? Empirical estimates for European firms. Research Policy 27, 127-141.

Asheim, B., Gertler, M., 2005. In: Fagerberg, Mowery, Nelson (Eds.), The Geography of Innovation: Regional Innovation Systems.

Athreye, S., Keeble, D., 2002. Specialized markets and behaviour of firms: evidence from the United Kingdom's regional economies. International Regional Science Review 25 (1), 38-62.

Audretsch, D., 1998. Agglomeration and the location of innovative activity. Oxford Review of economic policy 14-2, 18-29.

Bania, N., Calkins, L.N., Dalenberg, D.R., 1992. The effects of regional science and technology policy on the geographic distribution of industrial R\&D laboratories. Journal of Regional Science 32 (2), 209-228.

Baumert, T.H., 2007. In: Buesa, Heijs, et al. (Eds.), Los determinantes de la innovación regional en España y la Unión Europea.

Baumert, T.H., 2006. Los determinantes de la innovación. Un Estudio aplicado sobre las regiones de la Unión Europea. Ph. D. Thesis. Universidad Complutense de Madrid. http://www.ucm.es/bucm/cee/iaif. 
Baumert, T.H., Heijs, J., 2002. Los determinantes de la capacida innovadora regional: Una aproximación econométrica al caso español: Recopilación de estudios y primeros resultados. Documento de trabajo n॰33. Instituto de Análisis Industrial y Financiero, Universidad Complutense Madrid. http://www.ucm.es/bucm/cee/iaif and http://www.madrimasd.org.

Beaudry, C., Breschi, S., 2003. Are firms in clusters really more innovative? Economics of Innovation and New Technology 12, 325-342.

Berge, F., Grasse, A., 2004. Föderalismus in Belgien: vom Bundesstaat zum Staatenbund?, vol. 6. KonradAdenauer-Stiftung, Auslandsinfo.

Blind, K., Edler, J., Frietsch, R., Schmoch, U., 2003. Erfindungen kontra Patente. Schwerpunk studie zur technologischen Leistungsfähigkeit Deutschlands. Endberichtfür das Bundesministerium für Bildung und Forschung (BMBF). Fraunhofer Institut für Systemtechnik und Innovationsforschung, Karlsruhe.

Bottazzi, L., Peri, G., 2001. Innovation, demand and knowledge spillovers: theory and evidence from european regions. IGIER Working Paper (153), http://www.igier.uni-bocconi.it.

Bottazzi, L., Peri, G., 2003. Innovation and spillovers in regions: evidence from European Patent Data. European Economic Review (47), 687-710.

Brouwer, E., Kleinknecht, A.H., 1999. Innovative output and a firm's propensity to patent: an exploration of CIS microdata. Research Policy 28 (6).

Buesa, M., 2005. In: Muñoz (Dir.). Innovación.

Buesa, M., Heijs, J., et al., 2007. Sistemas regionales de innovación: nuevas formas de análisis y medición. Madrid.

Buesa, M., Baumert, Th., Heijs, J., MartínezPellitero, M., 2003a. Los factores determinantes de la innovación: un análisi seconométrico sobre las regiones españolas. Economía Industrial 2002/V (347), 67-84.

Buesa, M., Heijs, J., Martínez Pellitero, M., Baumert, Th., 2005. Regional systems of innovation and the knowledge production function: the Spanish case. Technovation 26, 436-472.

Buesa, M., MartínezPellitero, M., Heijs, J., Baumert, Th., 2003b. Los sistemas regionales de innovación en España: un atipología basada en indicadores económicos e institucionales de las Comunidades Autónomas. Economía Industrial 2002/V (347), 15-32.

Buesa, M., Navarro, M., et al., 2001. Indicadores de la ciencia, la tecnología y la innovación: metodología and fuentes para la CAPV and Navarra. Azkoaga Cuadernos de ciencias sociales and económicas (9).

Carree, M., Thurik, R., 1999. In: Audretsch, Thurik (Eds.), Industrial Structure and Economic Growth.

Christensen, J.L., 1992. In: Lunvall (Ed.), The Role of Finance in National Innovations Systems.

Chiuh-C.C., C. Y., A Bayesian Analysis of the Deming Cost Model with Normally Distributed Sampling Data, Quality Engineering, 18:107-116, 2006, Taylor \& Francis Group, LLC, ISSN: 0898-2

Cohen, W.M., Levin, R., 1989. In: Schmalensee, Willig (Eds.), Empirical Studies of Innovation and Market Structure.

Cooke, P.H., 1998. In: Braczyk, Cooke, Heidenreich (Eds.), Introduction: Origins of the Concept.

Cooke, P.H., Boekholt, P., Tödtling, F., 2000. The Governance of Innovation in Europe. Regional Perspectives on Global Competitiveness. London, New York.

Cooke, P.H., Morgan, K., 1994. In: Dodgson, Rotwell (Eds.), The Creative Milieu: A Regional Perspective on Innovation.

Crespi, F., 2004. Notes on the Determinants of Innovation: a Multi-Perspective Analysis. Fondazione Eni Enrico Mattei Note di Lavoro 42. 
De Falco S., Trupiano G. , Arnò Anna, "Certifying Innovation: A Proposal For A Standard With Ims", ECIE (European Conference on Innovation and Entrepreneurship) 2012 20-21 September, Santarem, Portugal.

De La Fuente, A., 2003. Convergence equations and income dynamics: the source of OECD convergence, 19701995. Economica 70, 655-671.

Dernis, H., Guellec, D., van Pottelsberghe, B., 2001. Using Patent Counts for Crosscountry Comparisons of Technology Output, STI Review no. 27. OECD, Paris.

Dosi, G., 1982. Technological paradigms and technological trajectories. Research Policy 11, 147-162.

Dosi, G., 1988. Sources, procedures and microeconomic effects of innovation. Journal of Economic Literature $26,1120-1171$.

Edquist, C.H., 2005. In: Fagerberg, Mowery, Nelson (Eds.), Systems of Innovation: Perspectives and Challenges.

EUROSTAT, 1994. The Community Innovation Survey. Status and perspectives. EuroStat, Luxemborg. EUROSTAT, 1996. The regional dimension of R\&D and innovation statistics. EU Commission, Luxembourg. Evangelista, R., 1996. Embodied and disembodied innovative activities: evidence from the Italian innovation survey. In: Innovation, Patents and Technological Strategies. OECD, Paris.

Evangelista, R., Sandven, T., Sirilli, G., Smith, K., 1998. Measuring innovation in European industry. International Journal of Economics and Business 3 (5), 311-333. Evangelista, R., 2000. Sectoral patterns of technological change in services. Economics Innovation 9, 183-221.

European Commission, 2001. Recherche et développement: statistiques annuelles. Luxembourg.

Faber, J., Hesen, A.B., 2004. Innovation capabilities of European nations. Cross national analyses of patents and sales of product innovations. Research Policy 33, 193-207.

Fagerberg, J., Verspagen, B., 1996. Heading for divergence? Regional growth in Europe reconsidered. Journal of Common Market Studies 34, 431-448.

Fagerberg, J., Verspagen, B., Canie'ls, M., 1997. Technology gaps, growth and unemployment across European regions. Regional Studies 31.

Fagerberg, J.,Mowery,D., Nelson, R. (Eds.), 2005. The Oxford Handbook of Innovation. Oxford, New York.

Iammarino, S., Prisco, M.R., Silvani, A., 1995. On the importance of regional innovation flows in the EU: some methodological issues in the Italian case. Research Evaluation 5 (3), 189-206.

Iammarino, S., Prisco, M.R., Silvani, A., 1996. La struttura regionale dell'innovazione. Economia e Politica Industriale 89, 187-229.

Kline, G.J., Rosenberg, N., 1986. An overview of innovation. In: Landau, R., Rosenberg, N. (Eds.), The Positive Sum Strategy: Harnessing Technology for Economic Growth. National Academy Press, Washington, DC. Lundvall, B.A., 1992. National Systems of Innovation.

OECD, 1992. OECD proposed guidelines for collecting and interpreting technological innovation data. "Oslo Manual". OECD, Paris.

OECD, 1994. Proposed Standard Practice for Surveys of Research and Experimental Development. The Measurement of Scientific and Technical Activities Using Patent Data as Science and Technology Indicators. "Frascati Manual". OECD, Paris.

OECD, 1996. Proposed Guidelines for Collecting and Interpreting Technological Innovation Data. "Oslo Manual" (revised version). OECD, Paris.

Quah, D.T., 1996. Regional convergence clusters across Europe. CEPLSE Discussion Paper 274.

Pinter, London. Neven, D.J., Gouyette, C., 1994. Regional convergence in the European Community. CEPR Discussion Paper 914.

Van Raan, A.F. (Ed.), 1988. Handbook of Quantitative Studies of Science and Technology. Elsevier, NorthHolland. 